\title{
ERRATUM
}

Donna A. Volpe $\cdot$ De-lin Du $\cdot$ Charles K. Grieshaber

Martin J. Murphy, Jr.

\section{In vitro characterization of the myelotoxicity of cyclopentenyl cytosine}

In: Cancer Chemotherapy and Pharmacology (1994) 34: 103-108

On page 105 of the above contribution the legend to Fig. 3 contains an error in line 2 (CFU-gm should read CFU-e). The complete legend is as follows:

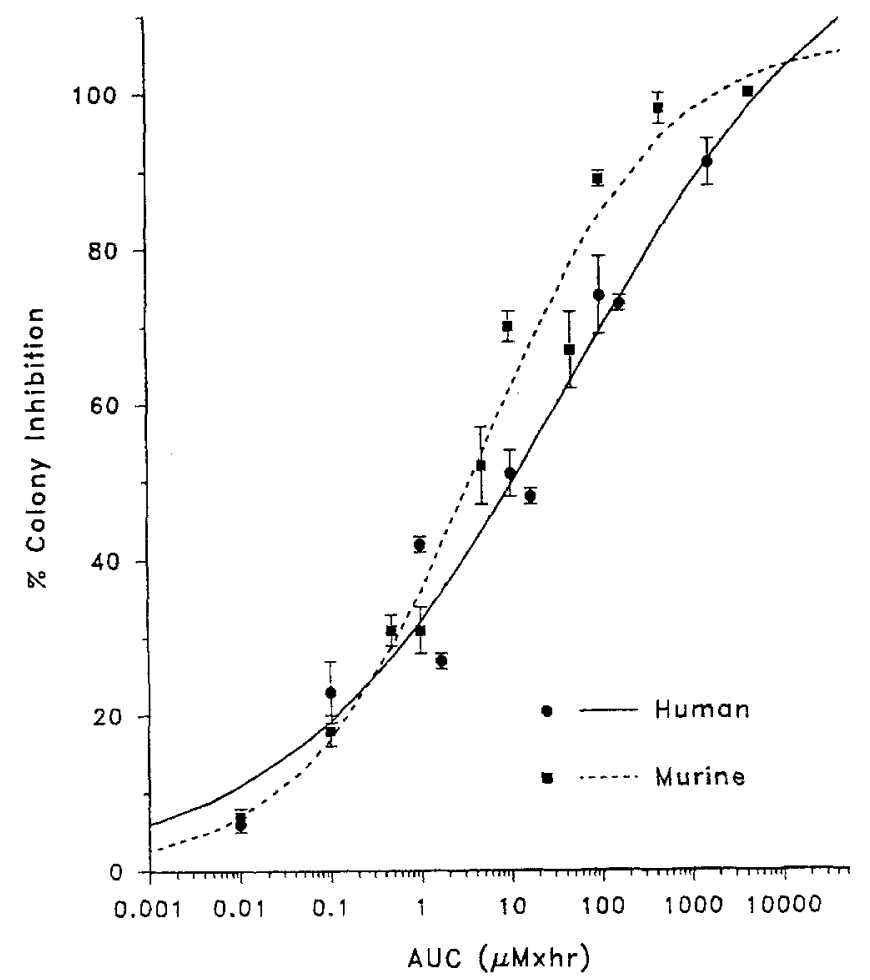

Fig. 3. Effects of CPE-C exposure on human (-C) and murine (1.- CFU-e. Symbols represent mean values $\pm \mathrm{SE}$ for 3 individual experiments; lines were generated from the Emax equation. Each experiment consisted of 6 capillaries (human) or 3 dishes (murine)

Donna A. Volpe - De-lin Du - Martin J. Murphy, Jr.

Hipple Cancer Research Center, Dayton, OH, USA

Charles K. Grieshaber

National Cancer Institute, Bethesda, MD, USA 